\title{
Change of bacterial community structure in nonylphenols-degrading sediments
}

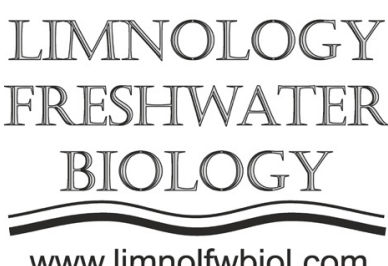

www.limnolfwbiol.com

\author{
Kuzikova I.L. ${ }^{1 *}$, Zaytseva T.B. ${ }^{1}$, Andronov E.E. ${ }^{2}$, Safronova V.I. ${ }^{2}$, Medvedeva N.G. ${ }^{1}$ \\ ${ }^{1}$ Scientific Research Centre for Ecological Safety of the Russian Academy of Sciences (SRCES RAS), 18, Korpusnaya ul., Saint- \\ Petersburg, 197110, Russia \\ ${ }^{2}$ All-Russia Research Institute for Agricultural Microbiology (ARRIAM), Sh. Podbelskogo 3, Saint-Petersburg, 196608, Russia
}

\begin{abstract}
The present study investigated the shift in bacterial community structure in response to $\mathrm{NP}$ attenuation in the Gulf of Finland bottom sediments. High levels of $\mathrm{NP}_{\mathrm{s}}(300 \mathrm{mg} / \mathrm{kg})$ in sediments can be biodegraded by the autochthon microorganisms. $\mathrm{NP}_{\mathrm{s}}$ addition showed no impact on diversity of microbial community structure. However, $\mathrm{NP}_{\mathrm{s}}$ amendment led to significant change in bacterial community structure in $\mathrm{NP}_{\mathrm{s}}$ - amended microcosm. Illumina MiSeq sequencing analysis indicated that Firmicutes, Gammaproteobacteria, Deltaproteobacteria were the three most abundant bacterial groups in $\mathrm{NP}_{s}$-degrading sediment, suggesting that these groups might have a specific role in $\mathrm{NP}_{s}$ degradation. The involvement of a wide range of microorganisms related to $\mathrm{NP}_{\mathrm{s}}$ biodegradation enlarges the possible risk of reduction of $\mathrm{NP}_{s}$ in environment.
\end{abstract}

Keywords: nonylphenols, bottom sediments, biodegradation, bacterial community, Illumina MiSeq sequencing

Nonylphenols $\left(\mathrm{NP}_{\mathrm{s}}\right)$ - are toxic, xenobiotic substances classified as endocrine disruptors, which have a negative effect on the hormonal system of humans, fish, and other organisms. NPs are ubiquitous in many environmentally relevant matrices (e.g. influent and effluent water from sewage treatment plants, reservoirs, river water, lake water, marine water, groundwater, bottom sediments and others) (Acir and Guenther, 2018). Once released in the aquatic environment, highly hydrophobic ( $\log \mathrm{Ko} /$ $\mathrm{w}=4.48) \mathrm{NP}_{\mathrm{s}}$ tend to adsorb to suspended matter and accumulate in bottom sediments. The $\mathrm{NP}_{s}$ content in sediments of marine and freshwater ecosystems are several orders of magnitude higher than that in water and can reach $3500 \mathrm{mg} / \mathrm{kg}$. Highly persistent in the aquatic environment, $\mathrm{NP}_{s}$ are accumulated by aquatic organisms and thus induce direct or indirect toxic effects in them (Staniszewska et al., 2017). Nonylphenols have been found to cause oxidative stress in cells of diatoms, green algae, cyanobacteria (Liu et al., 2010; Gao and Tam, 2011; Zaytseva et al., 2015; Medvedeva et al., 2017). Environmentally relevant concentrations of $\mathrm{NP}_{s}$ cause significant changes in activity of hydrolytic enzymes in the terrestrial fungi involved in organic matter degradation in bottom sediments. It was found that $\mathrm{NP}_{s}$ contributes to the activation of pigments, exopolysaccharides and proteolytic enzymes, considered as potential fungal virulence factors (Kuzikova et al., 2015; 2016; 2017). Biodegradation of
$\mathrm{NP}_{\mathrm{s}}$ can reduce the toxicological risk. The knowledge of the $\mathrm{NP}_{s}$ degradation potential in contaminated sediment is very important for the management of sediments for bioremediation.

Sediments (0-10 cm depth) used for microcosm construction was collected from Gulf of Finland in July 2018 (Kopor Bay located at 59.99186 $\mathrm{N}$ latitude and $28.96622^{\circ} \mathrm{E}$ longitude). In this microcosm experiment, initial concentration of NPs $(300 \mathrm{mg} / \mathrm{kg} \mathrm{dw})$ decreased to $121 \mathrm{mg} / \mathrm{kg} \mathrm{dw}$ during 240 days, whereas that in control microcosm with autoclaved sediments did not change, indicating that Gulf of Finland sediments contain NPs-degrading activity by microorganisms. The time taken for $50 \%$ of initial concentration of $\mathrm{NP}_{\mathrm{s}}$ to dissipate $\left(\mathrm{T}_{50}\right)$ based on a first-order model, was 177 days. Illumina MiSeq sequencing analysis indicated that the structure of the prokaryotic communities in the control sediment has been mainly formed by the phyla of Proteobacteria, Actinobacteria, Bacteroidetes, Firmicutes, Acidobacteria. Proteobacteria have the largest portions in the sediment microbiom. Our study indicated that according to the Shannon and Chao1 indices values, $\mathrm{NP}_{\mathrm{s}}$ addition showed no impact on diversity of microbial community structure. However, $\mathrm{NP}_{\mathrm{s}}$ amendment led to significant change in bacterial community structure in $\mathrm{NP}_{\mathrm{s}}$ - amended microcosm. Firmicutes (34.4\%), Gammaproteobacteria (22.6\%), Deltaproteobacteria (7.4\%) were the largest bacteria groups in $\mathrm{NP}_{\text {s }}$ degrading sediment after 240 days of incubation. The

*Corresponding author.

E-mail address: ilkuzikova@ya.ru (I.L. Kuzikova)

(C) Author(s) 2020. This work is distributed under the Creative Commons Attribution 4.0 License. 
relative share of archaea and Bacteroidetes decreased and share of Actinobacteria, Firmicutes and Chloroflexi increased in the $\mathrm{NP}_{\mathrm{s}}$ - amended microcosm. In this study, 10 bacterial strains capable to degrade the nonylphenols were isolated from $\mathrm{NP}_{\mathrm{s}}$ contaminated bottom sediments. By sequencing a fragment of the $16 \mathrm{~S}$ rRNA gene sequence, the most active strain Bacterium sp. 8 was identified as Raoultella planticola (Phylum: Proteobacteria; Class: Gammaproteobacteria).

In conclusion, high levels of $\mathrm{NP}_{\mathrm{s}}(300 \mathrm{mg} / \mathrm{kg})$ in sediment can be biodegraded by the autochthon microorganisms. $\mathrm{NP}_{\mathrm{s}}$ addition showed no impact on diversity of microbial community structure. $\mathrm{NP}_{\mathrm{s}}$ amendment and subsequent biodegradation significantly induced the shift in the bacterial community structure in the $\mathrm{NP}_{s}$-amended microcosm. Firmicutes, Gammaproteobacteria, Deltaproteobacteria were the three most abundant bacterial groups in $\mathrm{NP}_{\mathrm{s}}$-degrading sediment, suggesting that these groups might have a specific role in $\mathrm{NP}_{\mathrm{s}}$ degradation. The involvement of a wide range of microorganisms related to $\mathrm{NP}_{\mathrm{s}}$ biodegradation enlarges the possible risk reduction of $\mathrm{NP}_{\mathrm{s}}$ in environment.

\section{References}

Acir I.H., Guenther K. 2018. Endocrine-disrupting metabolites of alkylphenol ethoxylates - a critical review of analytical methods, environmental occurrences, toxicity, and regulation. Science of the Total Environment 635: 15301546. DOI: $10.1016 /$ j.scitotenv.2018.04.079

Gao Q.T., Tam N.F.Y. 2011. Growth, photosynthesis and antioxidant responses of two microalgal species, Chlorella vulgaris and Selenastrum capricornutum, to nonylphenol stress. Chemosphere 82(3): 346-354. DOI: $10.1016 / \mathrm{j}$. chemosphere.2010.10.010

Kuzikova I., Safronova V., Medvedeva N. 2016. Impact of nonylphenol on the physiological activity of fungi from the coastal area of the Gulf of Finland. In: International Conference "Managing Risks to Coastal Regions and Communities in a Changing World". DOI: 10.21610/ conferencearticle_58b431765a62a

Kuzikova I., Safronova V., Zaytseva T. et al. 2017. Fate and effects of nonylphenol in the filamentous fungus Penicillium expansum isolated from the bottom sediments of the Gulf of Finland. Journal of Marine Systems 171: 111-119. DOI: 10.1016/j.jmarsys.2016.06.003

Kuzikova I.L., Tileva E.A., Zaytseva T.B. et al. 2015. Effect of nonylphenol on terrigenous fungi of the coastal zone of eastern part of Gulf of Finland. Mikologiya i Fitopatologiya [Mycology and Phytopathology] 49(4): 249-256. (in Russian)

Liu Y., Guan Y., Gao Q. et al. 2010. Cellular responses, biodegradation and bioaccumulation of endocrine disrupting chemicals in marine diatom Navicula incepta. Chemosphere 80: 592-599. DOI: 10.1016/j.chemosphere.2010.03.042

Medvedeva N., Zaytseva T., Kuzikova I. 2017. Cellular responses and bioremoval of nonylphenol by the bloomforming cyanobacterium Planktothrix agardhii 1113. Journal of Marine Systems 171: 120-128. DOI: 10.1016/j. jmarsys.2017.01.009

Staniszewska M., Graca B., Sokołowski A. et al. 2017. Factors determining accumulation of bisphenol A and alkylphenols at a low trophic level as exemplified by mussels Mytilus trossulus. Environmental Pollution 220: 1147-1159. DOI: 10.1016/j.envpol.2016.11.020

Zaytseva T.B., Medvedeva N.G., Mamontova V.N. 2015. Peculiarities of the effect of octyl- and nonylphenols on the growth and development of microalgae. Inland Water Biology 8(4): 406-413. DOI: 10.1134/S1995082915040161 